\title{
Four-year outcomes after minimally invasive transiliac sacroiliac joint fusion with triangular titanium implants
}

This article was published in the following Dove Press journal:

Medical Devices: Evidence and Research

\section{Emily Darr' \\ Daniel Cher ${ }^{2}$}

'Physical Medicine \& Rehabilitation, Medical University of South Carolina, Charleston, SC, USA; ${ }^{2}$ Clinical Affairs, SI-BONE, Inc., Santa Clara, CA, USA

Correspondence: Emily Darr Medical University of South Carolina, 96 Jonathan Lucas Street, CSB 700,

Charleston, SC 29425, USA

$\mathrm{Tel}+\mathrm{I} 6184069649$

Email darr@musc.edu
Background: Increasing long-term evidence supports the safety and effectiveness of minimally invasive sacroiliac joint fusion (SIJF) for sacroiliac joint (SIJ) dysfunction, an important cause of chronic low-back/buttock pain.

Objective: To report 4-year follow-up in patients undergoing SIJF using triangular titanium implants (TTI) as part of two prospective trials.

Methods: We enrolled 103 subjects at 12 centers treated with TTI in two prospective clinical trials (NCT01640353 and NCT01681004) and followed them in the current study (NCT02270203), with clinic visits at 3, 4, and 5 years.

Results: At 4 years, mean SIJ pain scores (available in 91 subjects [88.3\%]) had decreased by 54 points from baseline; disability (Oswestry Disability Index) scores decreased by 26 points; and quality of life (EuroQOL-5D) improved by 0.3 points $(0-1$ scale). Satisfaction rates were high and the proportion of subjects taking opioids decreased from $77 \%$ at baseline to $43 \%$ at 4 -year follow-up. Conclusion: Four-year follow-up showed continued excellent responses in patients with SIJ pain treated with SIJF using triangular titanium implants.

Keywords: sacroiliac joint fusion, chronic low back pain, multicenter prospective trial

\section{Introduction}

Approximately $15 \%-30 \%$ of all chronic low-back pain involves the sacroiliac joint (SIJ). ${ }^{1-5}$ Increasing evidence supports the safety and effectiveness of SIJ fusion in patients with chronic SIJ dysfunction, and several device systems are now available. The most commonly studied device - triangular titanium implants (iFuse Implant System, SI-BONE, Santa Clara, CA, USA) - is supported by prospective clinical trials ${ }^{6-8}$ as well as a pooled analysis of those trials ${ }^{9}$ and numerous case series. ${ }^{10-18}$ Herein, we report 4-year prospective follow-up, updating a previously published report of the same cohort at 3 years. ${ }^{19}$

\section{Methods}

As previously described, subjects in this study (LOIS, Long Term Outcomes from INSITE and SIFI, NCT02270203) were enrolled at 12 centers that participated in two feeder trials: INSITE (NCT01681004, a prospective, randomized controlled trial of SIJ fusion vs non-surgical management $)^{6}$ or SIFI (NCT01640353, a prospective multicenter single-arm study). ${ }^{8}$ In both feeder studies, patients with SIJ pain - diagnosed by history, physical examination, and confirmatory diagnostic SIJ block with local anesthetic - underwent placement of triangular titanium implants in a lateral transiliac fashion during a brief (typically $<1$ hour) surgery. In the feeder studies, subjects had 
scheduled follow-up visits up to 2 years. The published 2-year reports showed marked, immediate, and sustained improvements in pain, disability, and quality of life. ${ }^{6,8}$

Subjects at selected centers enrolled into the current study, which had similar study visits at years 3, 4, and 5 after initial surgery, with telephone visits at $2.5,3.5$, and 4.5 years to maintain contact with participants. At each clinic visit, subjects completed surveys to assess SIJ pain scores using a visual analog (0-100) scale, disability related to back pain as assessed by the Oswestry Disability Index $(0=$ no disability due to back pain to $\geq 60=$ completely disabled), ${ }^{20}$ using quality of life ([EuroQOL-5D]; on a 0 [death] to 1 [perfect health] scale), ${ }^{21}$ overall satisfaction with the procedure, and use of opioid medications for SIJ pain. Questionnaires were identical to those used in the two feeder studies and were administered by trained study research coordinators. Furthermore, study coordinators recorded all negative changes in health as adverse events. The relatedness of the reported event to the index procedure or devices used during the procedure was assessed by the treating physician. All centers obtained institutional review board approval for study conduct.

\section{Results}

Of the 103 enrolled subjects, 93 (90.3\%) completed 4-year follow-up. Marked improvements in pain (54 points), disability ( 26 points), and quality of life ( 0.3 points), previously observed at 3 years, were maintained at 4 years (Figure 1). Satisfaction rates remained high, except for a slight reduction in the proportion who were very satisfied. The proportion of subjects taking daily opioids decreased from $77 \%$ immediately prior to surgery to $43 \%$ at the 4 -year follow-up.

In total, 114 adverse events were reported between years 3 and 4; however, none were rated as probably or definitely related to the study devices or index surgical procedure. Many events indicated underlying degenerative disease associated with age and osteoarthritis (eg, hip, knee, shoulder, neck, and
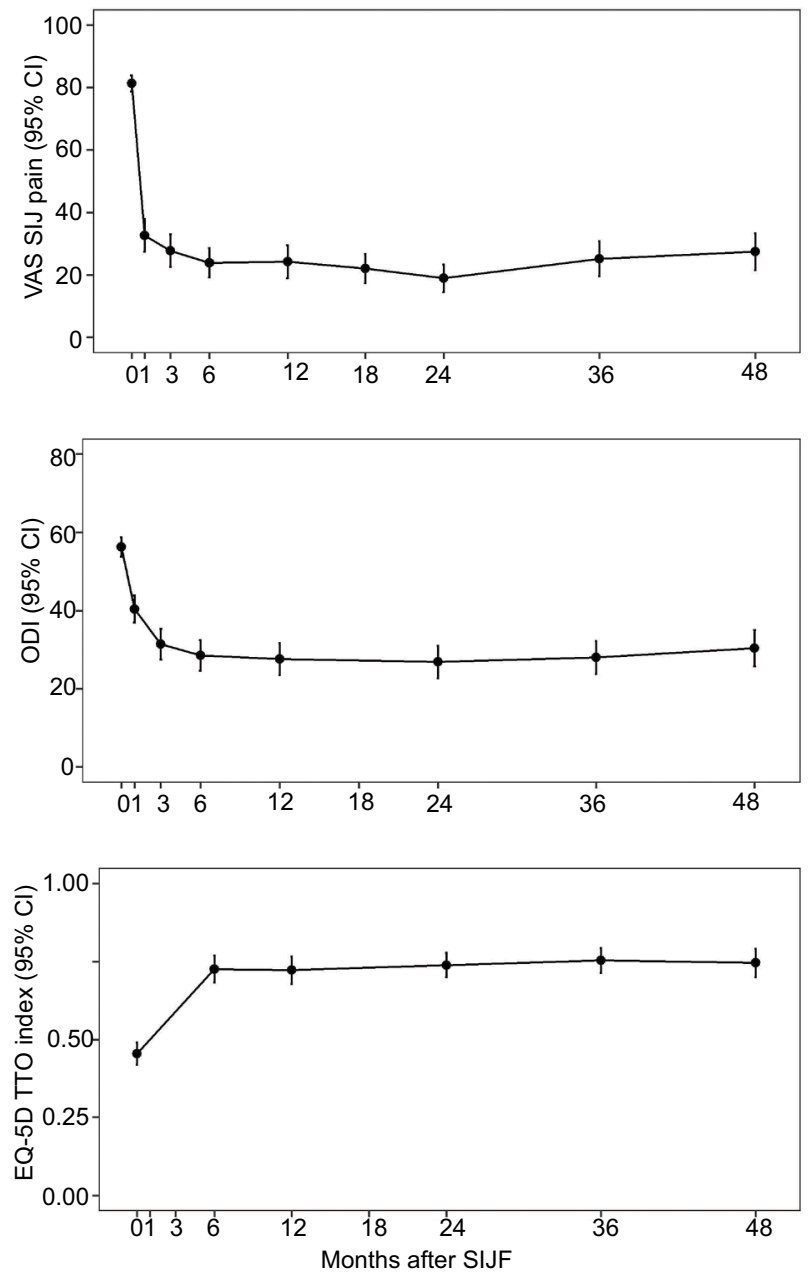

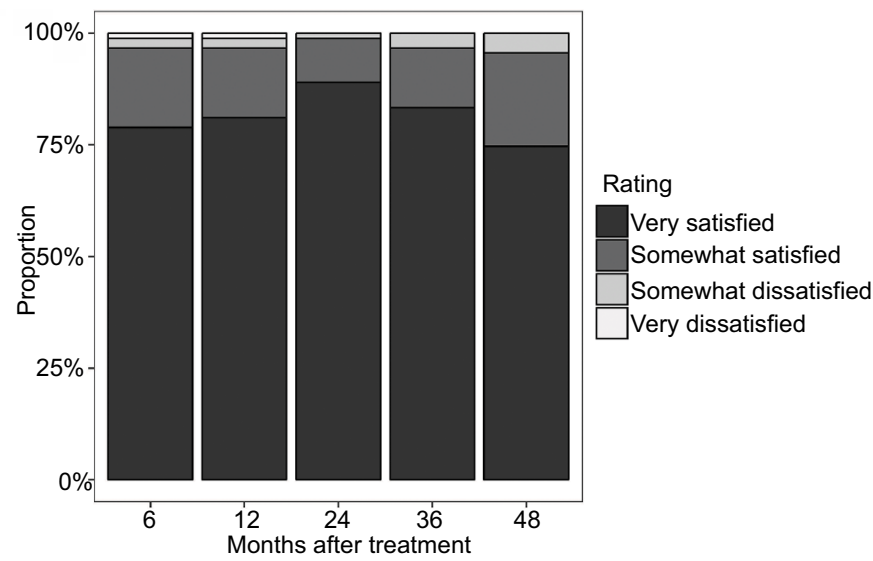

Figure I Left: Improvement in SIJ pain (top), dysfunction due to pain (ODI, middle), and quality of life (EQ5D-TTO, bottom). Right: patient satisfaction levels. Abbreviations: SIJ, sacroiliac joint; SIJF, sacroiliac joint fusion; ODI, Oswestry Disability Index; EuroQOL-5D, quality of life; EQ5D-TTO, EuroQOL-5D time trade-off index. 
lumbar spine osteoarthritic degeneration). Other than one previously reported subject who underwent surgical revision of the target SIJ at 3.8 years, no other subjects underwent revision procedures between years 3 and 4 .

\section{Discussion}

In the past, surgeons overlooked the SIJ as a cause of chronic low-back pain, probably because no feasible surgical treatment was available. Our data, reporting the longest prospective follow-up to date, show that SIJ fusion with triangular titanium implants can provide marked and sustained relief of pain, disability, and quality of life in patients for whom no other treatment had provided clinically important relief. Observed improvements were as large as those seen in other commonly conducted spine surgeries. Our data stand in marked contrast to non-surgical treatments, which have shown poor rates of pain relief and increased opioid use. ${ }^{22}$

\section{Summary}

In two prospective clinical trials, 103 subjects with sacroiliac joint dysfunction underwent SIJ fusion with triangular titanium implants. At 4-year follow-up, clinical outcomes were preserved, with no new adverse events related to the index procedure or devices.

\section{Acknowledgment}

SI-BONE sponsored this clinical trial.

\section{Disclosure}

Emily Darr conducts clinical research as part of prospective trials sponsored by SI-BONE. Daniel Cher is an employee of SI-BONE. The authors report no other conflict of interest in this study.

\section{References}

1. Bernard TN, Kirkaldy-Willis WH. Recognizing specific characteristics of nonspecific low back pain. Clin Orthop Relat Res. 1987;(217):266-280.

2. Schwarzer AC, Aprill CN, Bogduk N. The sacroiliac joint in chronic low back pain. Spine. 1995;20(1):31-37.

3. Maigne JY, Aivaliklis A, Pfefer F. Results of sacroiliac joint double block and value of sacroiliac pain provocation tests in 54 patients with low back pain. Spine. 1996;21(16):1889-1892.
4. Irwin RW, Watson T, Minick RP, Ambrosius WT, Age AWT. Age, body mass index, and gender differences in sacroiliac joint pathology. Am J Phys Med Rehabil. 2007;86(1):37-44.

5. Sembrano JN, Polly DW. How often is low back pain not coming from the back? Spine. 2009;34(1):E27-E32.

6. Polly DW, Swofford J, Whang PG, et al. Two-Year Outcomes from a Randomized Controlled Trial of Minimally Invasive Sacroiliac Joint Fusion vs. Non-Surgical Management for Sacroiliac Joint Dysfunction. Int J Spine Surg. 2016;10:28.

7. Duhon BS, Bitan F, Lockstadt H, et al. Triangular Titanium Implants for Minimally Invasive Sacroiliac Joint Fusion: 2-Year Follow-Up from a Prospective Multicenter Trial. Int J Spine Surg. 2016;10:13.

8. Dengler JD, Kools D, Pflugmacher R, et al. 1-Year Results of a Randomized Controlled Trial of Conservative Management vs. Minimally Invasive Surgical Treatment for Sacroiliac Joint Pain. Pain Physician. 2017;20(6):537-550.

9. Dengler J, Duhon B, Whang P, et al. Predictors of Outcome in Conservative and Minimally Invasive Surgical Management of Pain Originating From the Sacroiliac Joint: A Pooled Analysis. Spine. 2017;42(21):16641673. Epub March 27, 2017.

10. Rudolf L. Sacroiliac Joint Arthrodesis-MIS Technique with Titanium Implants: Report of the First 50 Patients and Outcomes. Open Orthop J. 2012;6(1):495-502.

11. Rudolf L. MIS Fusion of the SI Joint: Does Prior Lumbar Spinal Fusion Affect Patient Outcomes? Open Orthop J. 2013;7:163-168.

12. Sachs D, Capobianco R. One year successful outcomes for novel sacroiliac joint arthrodesis system. Ann Surg Innov Res. 2012;6(1):13.

13. Sachs D, Capobianco R. Minimally invasive sacroiliac joint fusion: one-year outcomes in 40 patients. Adv Orthop. 2013;2013:536128.

14. Cummings J, Capobianco RA. Minimally invasive sacroiliac joint fusion: one-year outcomes in 18 patients. Ann Surg Innov Res. 2013; $7(1): 12$.

15. Schroeder JE, Cunningham ME, Ross T, Boachie-Adjei O. Early results of sacro-iliac joint fixation following long fusion to the sacrum in adult spine deformity. HSS J. 2014;10(1):30-35.

16. Smith AG, Capobianco R, Cher D, et al. Open versus minimally invasive sacroiliac joint fusion: a multi-center comparison of perioperative measures and clinical outcomes. Ann Surg Innov Res. 2013;7(1):14.

17. Ledonio CG, Polly DW, Swiontkowski MF. Minimally invasive versus open sacroiliac joint fusion: are they similarly safe and effective? Clin Orthop Relat Res. 2014;472(6):1831-1838.

18. Ledonio CG, Polly DW, Swiontkowski MF, Cummings JT. Comparative effectiveness of open versus minimally invasive sacroiliac joint fusion. Med Devices. 2014;7(7):187-193.

19. Darr E, Meyer SC, Whang PG, et al. Long-term prospective outcomes after minimally invasive trans-iliac sacroiliac joint fusion using triangular titanium implants. Med Devices. 2018;11:113-121.

20. Fairbank JC, Pynsent PB. The Oswestry Disability Index. Spine. 2000;25(22):2940-2952; discussion 2952.

21. EuroQol Group. EuroQol-a new facility for the measurement of health-related quality of life. Health Policy Amst Neth. 1990;16(3): 199-208.

22. Vanaclocha V, Herrera JM, Sáiz-Sapena N, Rivera-Paz M, Verdú-López F. Minimally Invasive Sacroiliac Joint Fusion, Radiofrequency Denervation, and Conservative Management for Sacroiliac Joint Pain: 6-Year Comparative Case Series. Neurosurgery. 2018;82(1):48-55.
Medical Devices: Evidence and Research

\section{Publish your work in this journal}

Medical Devices: Evidence and Research is an international, peerreviewed, open access journal that focuses on the evidence, technology, research, and expert opinion supporting the use and application of medical devices in the diagnosis, monitoring, treatment and management of clinical conditions and physiological processes. The identification of novel
Dovepress

devices and optimal use of existing devices which will lead to improved clinical outcomes and more effective patient management and safety is a key feature. The manuscript management system is completely online and includes a quick and fair peer-review system. Visit http://www. dovepress.com/testimonials.php to read real quotes from authors. 